\title{
Leveraging Emergent Social Interactions for Value Co-Creation on Transaction Platforms
}

\author{
Rainer Schmidt \\ Munich University oAS \\ rainer.schmidt@hm.edu
}

\author{
Kathrin Kirchner \\ Technical University of Denmark \\ kakir@dtu.dk
}

\author{
Liana Razmerita \\ Copenhagen Business School \\ 1ra.msc@ecbs.dk
}

\begin{abstract}
Transaction platforms supporting the exchange of services and products between actor groups are the foundation of many new business models. Attracting enough actors by propositioning value is crucial for the success of transaction platforms. Therefore, the proper design of value creation mechanisms is a pre-condition to be successful. Initially, the focus of value creation was on network effects, but now the interactions between the actors are being examined more closely. Emergent social interactions (ESI) - are initiated by users on their initiative and are not subject to top-down planning. However, their impact on value creation on transaction platforms has not been researched in depth. Therefore, our paper investigates how emergent social interactions con-tribute to value co-creation mechanisms on transaction platforms. We apply a ServiceDominant Logic (S-D logic) theoretical lens and create a framework that describes the impact of emergent social interactions on value co-creation. Our framework integrates the moderation of ESI-based value-co-creation by market properties. Based on the framework, platform designers and entrepreneurs can better decide on the design of transaction platforms in general and the employment of emergent social interactions. Our theoretical contribution paves the way to developing methods for designing transactional platforms using emergent social interactions respecting the context set by market properties.
\end{abstract}

\section{Introduction}

Transaction platforms create value by leveraging transactions between independent actors, e.g., consumers and producers of products and/or services [1]. The platform operators act as intermediaries who enable transactions between two or more groups of actors [1]. Transaction platform-based business models are the most important business models of the 21 st century [2, 3 ]. For example, $60 \%$ of all start-ups in 2019 are based on platform strategies [4]. In addition, transaction platforms are the most important basis for new business ideas [5]. Seven out of the ten most valuable enterprises worldwide use platform-based business models (e.g., Alibaba, Amazon) [6].

Designing a transaction platform is a high-risk endeavor because many platforms fail because they do not attract enough users or investment capital [2]. Therefore, it is necessary to create methods that enable companies to design platforms successfully and minimize the risk of failure.

A key element for the successful design of transactional platforms is understanding their value creation mechanisms to attract enough actors. The scope of value creation has broadened in recent years. Starting from a network effects perspective [5], the value co-creation perspective [7], that integrates customers, partners, and stakeholders in mutual processes is becoming increasingly important.

Emergent Social Interactions (ESI) are social interactions individuals initiate without being planned or initiated by hierarchical structures [8]. Examples of ESI are social production, egalitarian decisions, and weak ties [8]. Social production is the collaborative creation of primarily digital artifacts, e.g., open-source software [9]. Egalitarian decisions replace expert-based decisions by merging a large number of individual decisions [10]. Weak ties are ad-hoc created connections between individuals [11].

We hypothesize that emergent social interactions impact value co-creation on transaction platforms and that this impact is moderated by the properties of the platform's market. Therefore, we formulate the following two research questions:

RQ1: How do emergent social interactions impact value co-creation on transaction platforms?

RQ2: Which implications for the design of transactional platforms can be derived from the influence of social interactions?

Our paper aims to create a framework that lets the designer of a platform recognize the necessity to use emergent social interactions and decide which emergent social interaction is relevant for the platform's purposes 
depending on market properties. Thus, we want to support the designer of platforms, whether an entrepreneur or incumbent enterprise, by giving means to decide on the use of emergent social interactions and the extent of their use. We also strive to make the influence of the market context on these decisions explicit.

We examine value creation on transaction platforms in two phases. Network effects initially determined value creation on platforms. Later, however, value co-creation plays an increasingly important role. Therefore, we develop a model of value co-creation on transaction platforms to describe the leverage points for emergent social interactions. We use a SD Logic-based theoretical lens [5]. It uses the four meta-theoretical foundations [7] of SD-Logic: Actor-to-actor networks, resource liquefaction, density, and integration.

Based on the recommendations from [12], we performed a literature review to identify existing literature of value co-creation on platforms such as [13]. Then we develop our framework that represents the influence of emergent social interactions on the value co-creation of transaction platforms with the help of the SD-logicbased transaction platform model. We show how social production, egalitarian decisions, and weak ties [8] impact actor-to-actor networks, resource liquefaction, resource density, and resource integration during the transaction phases attract, match, facilitate.

In a further step, we investigate how a market's properties modulate the impact of social interactions on value co-creation. Market properties like homogeneity of requirements, resource description complexity, and demand variance influence value co-creation on transaction platforms. We demonstrate our framework by applying it to existing transactional platforms and describing the impact of emergent social interactions on their value creation. In this way, we derive implications for the design of transaction platforms based on the impact of emergent social interactions and in the context of market properties.

\section{Theoretical Background}

To clarify the problem of designing transaction platforms, we depict the theoretical background of our work. It embraces transaction platforms and the transaction phases.

\subsection{Transaction Platforms}

Competition is taking place increasingly over platforms [14][15], and therefore, many companies are developing platform and service design strategies. However, they face several challenges [14], as major platform markets are winner-take-all markets. Research about platforms has changed its focus several times in recent decades. Starting 30 years ago, research has focused on innovation platforms that facilitate complementary products and services. An example of such an innovation platform with disruptive effects is the IBM $\mathrm{PC}$ and Windows platform in the 1980s [4]. A later focus of platform research has been on social platforms (e.g., Facebook) [16] whose goal is to support interactions between individuals using digital tools. Business models based on social platforms leverage the collected data and capture value by targeted advertising. Today, huge attention is spent on transactional platforms (e.g., Airbnb) that enable value creation between partners with the help of digital means that would not have been achieved without. Transaction platforms started to expand quickly with purely digital goods [17] [18] and services but later on extended to "online to offline" modes (O2O) [19]. They differentiate from traditional pipeline business models controlling a linear series of activities [14]. Chain reactions within platforms lead to the rapid growth of platforms and why platform markets are winner-takes-all markets [20, 21].

\subsection{Transaction Phases}

The activities on transaction platforms can be differentiated into three phases: the attraction of partners onto the transaction platform, the matching of value propositions by exchanging and filtering information, and the facilitation of the exchange of services.

To attract partners, it is necessary to describe the value propositions. They help to identify potential partners for service exchange and to inform about the offered value. The information does not have to be provided by the current actors themselves but by actors who have exchanged services in the past. A classic example is the description of holiday resorts and hotels on TripAdvisor by previous guests [22]. This description provides information on the offered services and an evaluation of these services, i.e., actors assess the value of the provided services. These contributions are public, and other actors often assess their value by establishing a quality assurance mechanism.

A variety of services are offered on one platform. The challenge is to match the best-fitting offers. Only a small part of all services is interesting for a specific actor. To ensure that the actors quickly find the relevant services, it is necessary to provide filtering mechanisms. These filtering mechanisms can be based on quite different concepts. The first possibility is the application of classical search mechanisms via keywords etc. The second possibility is the use of collaborative search mechanisms. The preferred services proposed to the actor will be those chosen by other actors with similar experiences in the past. It proposes services that are used by actors that are as similar as possible to the searching actor. 
Once the actors have agreed to exchange services, it is the task of the platform to facilitate the exchange. It should be as simple and efficient as possible. For a transaction platform, this means ensuring the appropriate provision of information. For home-sharing platforms such as Airbnb [23], information about the location of the apartment and the accessibility of the apartment is provided. In addition, information must also be provided on how to access the apartment, e.g., where the key is located. The property owner should make it as easy as possible for the tenant to pay for the apartment. In addition to the monetary currency, a social currency is also exchanged, supported by the platform. For example, the tenant evaluates the apartment he has occupied, and the landlord evaluates the guests' behavior.

\section{Model of Value Co-Creation on Trans- action Platforms}

The research on value co-creation on transaction platforms started focusing on low marginal cost and network effects [5]. Marginal cost is the cost of producing an additional service unit. The low marginal cost allows platforms to expand their business with minimal cost [14]. Network effects increase the value of a product as the number of consumers of the product increases [24]. Network effects can be differentiated into direct and indirect network effects [24]. Direct network effects increase the value for one group of actors by their increasing number [20]. Indirect network effects designate value for one actor group of the platform by increasing another group of actors [20].

The co-creation of value has been identified as a factor for successful platform design [25] and the complex structure of value co-creation in digital ecosystems [25]. A first example of analyzing a concrete platform with an SD-logic theoretical lens is provided in [23]; however, no general framework is given. To develop our value co-creation model on transaction platforms, we draw on the definition of value co-creation in Service-Dominant (S-D) Logic [26]. Value co-creation is defined as a set of actors that integrate resources (operant and operand) that are integrated, accepted, and exchanged in an ecosystem regulated by institutional arrangements [7]. To identify the leverage points of value co-creation on platforms, we use the four meta-theoretical foundations [7] of SD-Logic. These are actor-to-actor networks, resource liquefaction, resource density, and resource integration.

\subsection{Actor-to-Actor Structures}

Platforms are an emergent actor-to-actor structure that is self-contained and self-adjusting [7]. It offers an organizing logic for the actors to exchange services and co-create value [7]. Platforms support actor-to-actor structures during the three phases attract, match, and facilitate, as shown in Table 1. They attract actors and enable them to present and exchange value propositions. During the match phase, these propositions are filtered to offer relevant value propositions to the participants. Finally, transaction platforms support the exchange of services and currencies during the facilitate phase [27].

Table 1: Support of SD-Logic meta-theoretical foundations on transaction platforms

\begin{tabular}{|l|c|c|c|}
\hline & Attract & Match & Facilitate \\
\hline Actor-to-Actor S. & $\mathrm{x}$ & $\mathrm{x}$ & $\mathrm{x}$ \\
\hline R. Liquefaction & & $\mathrm{x}$ & \\
\hline R. Density & & $\mathrm{x}$ & $\mathrm{x}$ \\
\hline R. Integration & & & $\mathrm{x}$ \\
\hline
\end{tabular}

\subsection{Resource Liquefaction}

Liquefaction plays a crucial role by separating information from a physical representation [7]. In terms of resources, this concept means that information about resources can be more easily shared and made available to others. We provide an example of resource liquefaction in the travel sector. Before the internet, travelers had little information about the destination and accommodation and its quality. Today, resource liquefaction is provided on Booking.com or TripAdvisor [28] by providing digital information on services and products during the match phase.

\subsection{Resource Density}

Resource density describes whether resources can be quickly activated for an actor that wants to offer the desired service [7]. The maximum density is achieved when the best combination of resources is activated [29]. Resource density is supported by transaction phases during the match and facilitate phase. In these phases the available resources are listed and evaluated by using reviews and rating.

\subsection{Resource Integration}

One characteristic of platforms is their "outside-in" character meaning that resources come from outside. Their competitive advantage is not based on the holding of assets but on integrating and orchestrating external resources [17]. Therefore, resource integration is necessary on transaction platforms.

Following SD-Logic, resource integration is necessary because resources can never be used in isolation but need to be combined with other resources to increase 
their usefulness [7]. Platforms support resource integration by making previously isolated resources available in the match and facilitate phase. Platforms also provide means for combining resources with other resources on the platform. In this way innovation is enabled as the result of combining resources [30].

\section{The Impact of Emergent Social Inter- actions on Platform Value Co-creation}

To identify the research gap, we performed a literature review based on the recommendations in [12] and [31] using the search terms "platform" and "value-creation" and "social" on Google Scholar. Due to space limitations in this paper, we limited the search to recent papers starting from 2016 and analyzed the first 50 hits. The 18 sources categorized as relevant were analyzed further by reading the full text (see Table 2). Starting from this list of relevant papers, we started a graphbased search in two directions. First, we searched for related papers in the citations of the papers including literature from before 2016. Then we filtered the relevant papers by analyzing the abstracts. Second, we used the inverse citation search of Google Scholar, to search for papers that cited the papers considered as relevant and checked them for relevance. We then classified the relevant papers whether they address value creation co-creation and which kind of platform they focus on. Besides transaction platforms, we also considered innovation platforms [1] and social platforms [16]. We found that value creation is discussed for all three types of platforms. However, value co-creation is only investigated on innovation and social platforms. Hein et al. [32] analyze asymmetric innovation platforms. The investigations of social platforms [33] [34] do not consider transactions.

Table 2: Selected relevant papers

\begin{tabular}{|c|c|c|}
\hline & Value Creation & Value Co-Creation \\
\hline $\begin{array}{c}\text { Innovation } \\
\text { platforms }\end{array}$ & [35], [36] & [32], [37] \\
\hline $\begin{array}{c}\text { Transaction } \\
\text { Platforms }\end{array}$ & {$[38][39]$} & \\
\hline Social Platforms & $\begin{array}{c}{[40][16][41][42,43,} \\
44][45,46,47,48]\end{array}$ & [33] [34] \\
\hline
\end{tabular}

In our emergent social interactions (ESI) analysis, we take the model of Lusch, Vargo, and Tanniru in [29] and investigate how the ESIs social production, weak ties, and egalitarian decisions influence resource liquefaction and resource density. We draw on the three phases of transaction platforms to detail our analysis: attract, match, and facilitate. We start by analyzing how the information provided by social production supports the exchange of information on value propositions (see
Table 3). Then we show how egalitarian decisions support these platform phases by evaluating resources. Finally, weak ties connect people and support the exchange of services. The impact of social production, egalitarian decisions, and weak ties increase resource liquefaction and resources. This also leads to an increased co-created value.

Table 3: Impact of Emergent Social Interaction on Value CoCreation via the SD-Logic metatheoretical foundations

\begin{tabular}{|c|c|c|c|c|}
\hline & $\begin{array}{c}\text { Actor-to- } \\
\text { Actor } \\
\text { Networks }\end{array}$ & $\begin{array}{c}\text { Resource } \\
\text { Liquefac- } \\
\text { tion }\end{array}$ & $\begin{array}{c}\text { Resource } \\
\text { Density }\end{array}$ & $\begin{array}{c}\text { Resource } \\
\text { Integration }\end{array}$ \\
\hline $\begin{array}{c}\text { Social } \\
\text { Production }\end{array}$ & $\mathrm{x}$ & $\mathrm{x}$ & $\mathrm{x}$ & \\
\hline $\begin{array}{c}\text { Egalitarian } \\
\text { Decisions }\end{array}$ & & $\mathrm{x}$ & $\mathrm{x}$ & \\
\hline Weak Ties & $\mathrm{x}$ & & & \\
\hline
\end{tabular}

\subsection{Social Production}

Social production refers to an organization of production in which the steps and the associated results are determined by combining the decisions of individuals and not by a hierarchically prescribed plan [9]. Thus, social production implicitly creates an actor-to-actor network bottom up. This network is self-contained and selfadjusting [7]. Furthermore, it provides an organizing logic for the actors to exchange services [7].

Social production is an important means to increase resource liquefaction. The initiative to add or adapt information is not given by an external plan but is left to the initiative of the users. The decision about the information design is also up to the users. So, the user can decide on the type and amount of information used to describe the resources. The additional information on resources supports exchanging information on value propositions and filtering value propositions.

Social production also improves resource integration by enabling resource integration on behalf of independent decisions of individuals, not required to be part of a global plan from a hierarchical management organization. E.g., private rooms are resources integrated on the Airbnb platform by the decision of the owner. Comments and reviews of clients supplement the description of the room. Thus, the quality of integrated resources is assured by the public visibility of production results and the review of the community [8]. The publicity of contributions in social production leads to much more comprehensive quality control since it is in the producer's interest to fulfill all quality criteria and not only those set hierarchically [8]. The quantity and quality of the contributions increase as well as the social capital of the producer [9]. 


\subsection{Egalitarian Decisions}

Egalitarian decisions increase resource liquefaction by providing resource evaluations for those resources where an expert-based evaluation would not be feasible, e.g., because it would not be economical. Egalitarian decisions [49] are decisions based on an equal contribution of each participating person. Instead of identifying persons as "experts" that are attributed a higher degree of competency than others, egalitarian decisions are based on combining the individual decisions of the largest possible collective [8]. In this way expert-based decisions can be replaced by egalitarian decisions.

Egalitarian decisions also improve resource density by providing user ratings and comments that help select products and services. Especially for rarely used resources, it is difficult to identify experts a priori that properly determine the quality of the resources [17]. Thus, egalitarian decisions can provide more reliable information on the quality of resources.

\subsection{Weak Ties}

Weak Ties are relationships between individuals within organizations and across organizational boundaries that emerge without hierarchical definition, e.g., by chance or on the initiative of the individual [11].

Weak ties support the bottom-up creation of actorto-actor structures. Thus, they support the exchange of services on transaction platforms and the co-creation of value.

Weak ties also connect the people involved during service exchange and thus enable the exchange of knowledge as an operant resource. In this way, resource density is increased by weak ties.

\section{Modulation of Value co-creation by Market Properties}

The development of platforms is often under considerable time pressure, and only limited resources are available. Therefore, it is important to use the available resources in a targeted manner and prioritize the measures to build the platform on promising the fastest growth. Furthermore, being early in the market is a crucial success factor for platforms [2].

We do not assume that the identified contributions of ESI are equal for all platforms. Therefore, to allocate the available ones optimally, we develop a framework that describes the influence of external factors on the value co-creation by ESI. Therefore, we demonstrate our framework by showing how certain market properties modulate value co-creation by social interaction [25].
As discussed above, social production, weak ties, and egalitarian decisions increase resource liquefaction and density. We use three established factors from market theory [50]: homogeneity of value proposition, resource description, and demand variance.

First, we examine whether the homogeneous or heterogeneous requirements of platform users influence the added value. Then we examine whether the description of resources with few and quantitative criteria (as opposed to many and qualitative criteria) influences value co-creation. Finally, we also consider the influence of the variance of user demands, expressed as a short tail or long tail orientation, on value co-creation.

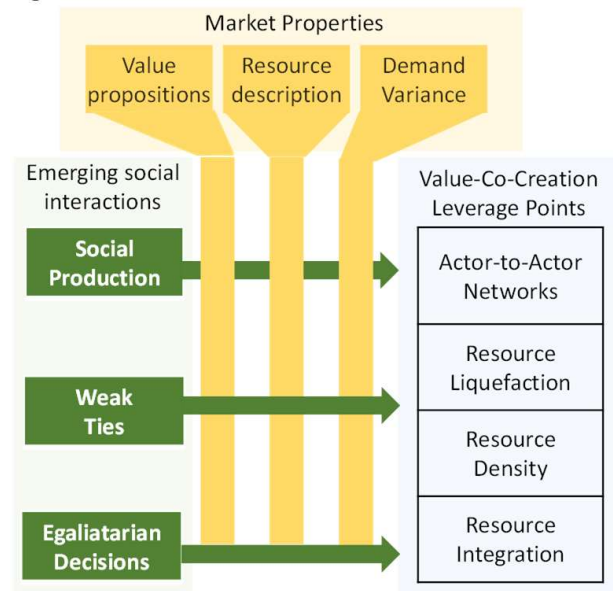

Figure 1: Framework describing the moderation of ESIbased value-co-creation by market-properties

\subsection{Homogeneity or Heterogeneity of Value propositions}

The value propositions on a platform may be homogeneous or heterogeneous. Homogeneous means that the value propositions can be abstracted to a common type parameterized and configured. An example of a platform with homogeneous value propositions is the ride-sharing platform Uber. The users want to be brought from A to B and have common speed, security, and comfort requirements. On the other hand, a platform with very heterogeneous value propositions is TripAdvisor. Its users have different expectations of what to do at many holiday locations: some want to visit cultural sites, and others sunbathe.

Resource Liquefaction - Customers create quite different descriptions and evaluations of the same resource on platforms with heterogeneous value propositions such as TripAdvisor. Through ESI, in particular social production, it is possible to capture this differentiated evaluation of resources regarding their fulfillment requirements. ESI are, therefore, particularly suitable for platforms with heterogeneous value propositions. 
Resource Density - The heterogeneity of value propositions also impacts the matching of user requests with service offerings. It causes that the same service that suits the requirements of user A well does not fulfill the requirements of user B at all. ESI provide the possibility to differentiate matching decisions according to the user's set of requirements. Again, the travel industry can serve as an example. ESI can help to have a high resource density because the needs of the travelers are very heterogeneous and the tourism services available are difficult to describe.

\subsection{Quantitative or Qualitative Resource Description}

The differentiation whether resources can be described with few and quantitative criteria or needs qualitative ones is orthogonal to the previous differentiation of value propositions. For, e.g., electronic parts can often be identified with a part number only; other resources such as wine are difficult to describe completely with quantitative elements only.

Resource Liquefaction - ESI enable the liquefaction of resources that need different qualitative criteria for description. Such a list is non-deterministic, which means it is impossible to specify the criteria in an a priori. Instead, emergent interactions such as social production help provide a resource description that is as comprehensive as possible.

Resource Density - Matching resources with different qualitative criteria with demand is much easier through emergent interactions, e.g., egalitarian decisions. The use of egalitarian decisions helps to consider the diversity of the matching criteria by using the similarity of the resources as a criterion.

Emergent social interactions are helpful if the resources cannot be described by a few clearly defined criteria but by many criteria that can only be represented qualitatively.

\subsection{Demand Variance}

Platforms can be differentiated according to the variance of demand. That means whether a short or long tail [51] strategy is pursued. Again, UBER may serve as an example of platforms with low variance. UBER offers one type of service, the transport from A to B. However, on other platforms, there is a high variance of service requests. For example, on TripAdvisor, highly frequented restaurants and restaurants with a very low demand can attract interest. That means TripAdvisor is pursuing a long tail strategy [51] to integrate services or resources seldom used. Nevertheless, it is necessary to assure resource liquefaction and resource density.
Resource Liquefaction - By using social production, the cost of creating the description can be reduced to near zero. Thus, social production enables the externalization of service and product description. The use of social production is especially important for platforms that support a long tail strategy. Through social production, products and services can be described and evaluated even if these are rarely in demand.

Resource Density - When selecting resources that belong to the long tail, there is often the problem that there are very few previous resource configurations. Classical mechanisms such as recommender systems are difficult to use. Here too, externalization (e.g., consumers comments etc.) offers a way out. Using the description already created by social production facilitated by egalitarian decisions such as evaluation and rating of services, decisions concerning long-tail resources can be externalized to users. In this way, many decisions become coachable in the first place, and the requirements are significantly reduced.

\section{Demonstration}

We demonstrate [52] the framework we have created by applying it to different transactional platforms and develop implications for platform design. For this purpose, we have created a cube (see Figure 2) visualizing the mediating impact of market properties on the value co-creation of platforms through ESI as described in the previous section. In this way, we can describe the combination of market properties with the highest or lowest impact on value co-creation.

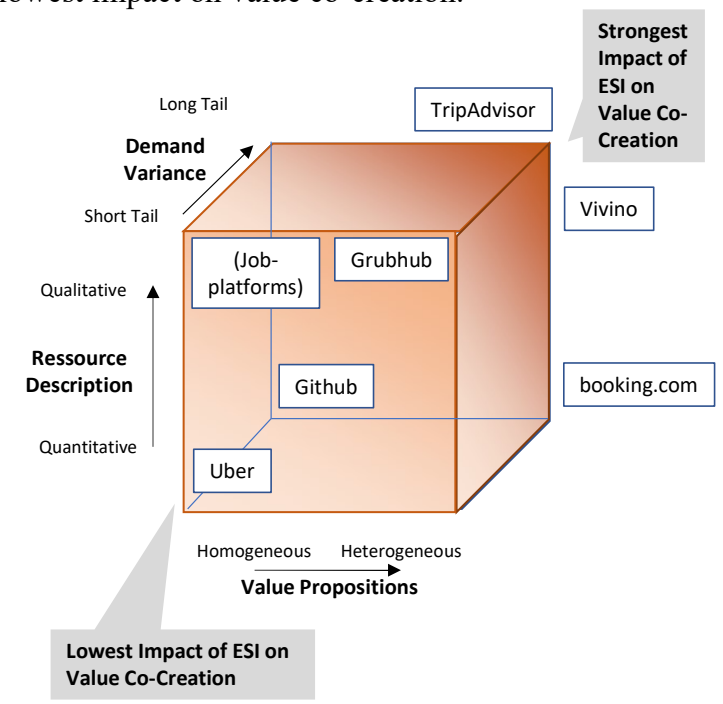

Figure 2: Cube of Value-Co-Creation influenced by Market-Properties

Using this cube of value co-creation, implications on platform design can be derived. The cube dimensions 
represent the three market properties that moderate the impact of ESI on value co-creation on platforms. They are homogeneity or heterogeneity of user requirements, quantitative or qualitative resource descriptions, and demand variance. The cube expresses that the usage of ESI is more effective. The higher the heterogeneity of the potential user requirements, the higher the number of qualitative criteria for the resources, and the stronger the long tail character of the platform is. Or visually: The closer a platform's characteristics are to the top, back corner, the more it relies on ESI and the associated usergenerated content.

To illustrate the cube, we have selected five different transaction platforms: Besides the already introduced traveling platforms Booking.com and TripAdvisor, we also consider the ride-share platforms like UBER, job-platforms like MTurk or Guru, food order and delivery platforms like Grubhub and, wine selection platforms like Vivino.

The tourist services on TripAdvisor have very heterogeneous value propositions (see Figure 2). For example, TripAdvisor discusses a wide range of holiday options. Therefore, it faces the challenge that the variety of holidays require quite different forms of description of tourism services are required. By using mechanisms such as social production, TripAdvisor can now offer suitable descriptions despite the great heterogeneity of the holidays. Demand for these kinds of holidays also varies, with TripAdvisor also covering both extremely sought-after tourism services and very exotic leisure endeavors with only a few bookings. Thus, TripAdvisor pursuits a long tail strategy [22]. Only through mechanisms such as social production we can create cost-effective descriptions and ratings for very rarely requested tourism services. The criteria used to describe tourism services are also highly qualitative and rarely quantified. ESI, such as social production and collective decisions, increase resource liquefaction and resource density on TripAdvisor.

In contrast to TripAdvisor, Uber deals with homogeneous value propositions of the clients since these essentially want to be transported from point A to point B. The description can be done by predominantly quantitative criteria such as distance duration, speed, etc. Furthermore, Uber focuses on metropolitan areas and experiences and therefore concentrates on high-turnover connections; Uber is pursuing a short tail strategy. Service description relies on automated data collection about speed driving comfort, etc. Emerging social interactions do not lead to additional value here.

While TripAdvisor and Uber represent the two extremes, the other platforms fall in-between. Job platforms have homogeneous value propositions like Uber through standardized job offerings. Also, there is not much demand variance, so a short tail strategy can be assumed. One difference, however, is the qualitative description of the resources offered (jobs), which is a similarity to TripAdvisor. Grubhub as a delivery service has a similar positioning but differs in the heterogeneity of its value propositions. Booking.com again has the heterogeneity of the value propositions and the long-tail support in common with TripAdvisor. Still, the resources can be described more quantitatively than qualitatively because they address hotel rooms.

These examples show how our framework can support the design of transaction platforms. Whether the user requirements are homogeneous or heterogeneous, whether the resources can be described employing quantitative or qualitative attributes, and what type of demand is prevailing, the importance of emergent social interactions can be decided.

\section{Discussion}

It is of crucial importance to allocate the resources for a platform to maximize value co-creation. To accomplish this, the understanding of the mechanism of value co-creation is decisive. Research on post-Tayloristic organizations identified three types of emergent interactions: social production, weak ties, and egalitarian decisions. Based on existing research [8], we show that ESI play a crucial role in creating business value that needs to be considered in the design of platforms [25] [53].

The paper aims to address two research questions. The first question focuses on how emergent social interactions impact value co-creation on transaction platforms. The second focuses on the implications for the design of transactional platforms that can be derived from the influence of social interactions. To answer these questions, we provide two contributions to research. First, we propose a framework that describes the Impact of ESI on Value Co-creation based on constructs from S-D logic (see Table 3). Second, we propose a cube that describes the modulation of value co-creation (see Figure 2) according to 3 key market properties and social interactions.

Previous research on platform design has not addressed value co-creation through emergent social interactions. More general aspects of platform design, such as platform architecture, value co-creation logic, governance, and platform competition, are discussed [54]. Specialized findings from a three-year case study on the design of a multi-sided platform are presented in [55]. The challenges in the emergence phase of data ecosystems are analyzed in [56]. In [57], platform-based value co-creation is investigated; however, the authors focus on extrinsic factors such as risk and customer loyalty.

Trip Advisor is used to showing the importance of community-created content for value co-creation on platforms [22]. However, not so much research to value 
co-creation processes focusing on interactions on social media is available. Only a few other researchers address such an investigation of value co-creation on platforms beyond network effects: A broadened locus of value cocreation in ecosystems is advocated in [58]. An investigation of value co-creation practices in platform ecosystems is made in [32]. Haile and Altmann analyze the specific mechanisms of value co-creation on software service platforms in [45]. A case study on value co-creation through social media is presented in [33]. A value co-creation circle is suggested, and the key factors for developing a successful value co-creation circle on social commerce platforms are explored in [44]. We identified implications for the design of platforms based on the finding that value co-creation of ESI is particularly strong in markets with three properties: Heterogeneous user requirements, qualitative resource criteria, and high variance of demand typical in long-tail markets. Thus, ESI are particularly important for platforms in markets with these properties and must be prioritized to foster platform success.

Leveraging emergent social interactions support value co-creation but also service innovation and service design. In this way, service providers can obtain information from the users' ratings for improving existing services and extending and supplementing existing services. In addition, a service-type innovation is also possible that goes beyond the improvement of services. For example, users' posts can be used to understand users' needs and identify new types of services that users of a platform consider helpful. These can complement existing services to improve the overall impact on the customer.

While most platforms support simple service innovation from the start, developing new service-types places higher demands. The challenge is that this includes adding the new type of services to the services directory and ensuring comprehensive support of the services during the attract, match, and facilitate phases of the platform. Furthermore, a comparison between the offered services and the requested services should also consider the newly added service types during the match phase. Finally, the facility phase must also support the new service types. This means that new types of interactions between platform participants should be supported.

An example of renting holiday apartments illustrates our considerations. Comments of clients can be used to improve or innovate services. Triggered by comments from tenants of apartments, an innovation of the services can be made; for example, big towels can be provided for visiting the beach. A service-type innovation could be, for example, that it becomes possible for the users of apartments to book a "dining with locals" service where a local chef prepares a typical dish that combines the meal with a local cultural experience.

While adding towels can be implemented by simply extending the description of the existing service, the challenge in implementing the "dining with locals" service is more complex. Thus, the "dining with locals" service must appear as a separate posting entry which is also invoiced separately. Furthermore, the implementation of the "dining with locals" service must be planned and coordinated, i.e., on which day and at what time it must be executed. Several parameters are to be recorded, which are necessary for the configuration of the service. This starts with the number of people going further beyond their culinary preferences to exclude meals for various reasons (e.g., shell animal allergy).

\section{Conclusion and Future Research}

Most of the new business models are based on platforms. However, this also entails enormous risks as many platform-based business models fail, and few companies can assert themselves in a fiercely competitive marketplace. Designing transaction platforms for new business models requires understanding their mechanisms of value creation. The most widely used perspective is based on direct and indirect network effects, but it has not turned out to be sufficient to explain the value-added on platforms in their entirety.

We used a new perspective by introducing S-D Logic into the analysis of transaction platforms because it focuses on the interaction between the different individual actors. Using the meta-theoretical foundations of SD-Logic [7], we created a value co-creation model for transaction platforms.

We used the model to identify and describe the leverage points of ESI on value co-creation. They are actorto-actor networks, resource liquefaction, resource density, and resource integration.

We developed a framework that shows how ESI support the creation of actor-to-actor networks and increase resource liquefaction, density, and integration.

We further provide a cube-oriented model that describes the moderation of value-creation by ESI in different market contexts. We can show that the impact of ESI on value co-creation is particularly strong for markets with products that have a complex description, where clients have heterogeneous requirements and long-tail marketing prevails.

Our research is relevant for both practitioners and academic research. Companies can analyze the three criteria: value proposition (from homogeneous to heterogeneous user requirements), resource criteria (qualitative versus quantitative criteria), and variance of service requests (short versus a long tail), and thus verify the 
sustainability of platform concepts before their implementation. We also showed that transaction platforms benefit from emergent social interaction, especially if there are heterogeneous customer needs of complex products and services and a long-tail characteristic. ESI externalize the creation of content on platforms such as service descriptions and ratings.

Academic research can also benefit from our research. We extend the original S-D logic value co-creation model by applying it to transaction platforms and showing the influence of ESI on value co-creation. With its help, the value-added contribution of ESI can be presented much better than before.

We created a different perspective for looking at value co-creation on platforms in general. Furthermore, we showed how the impact of ESI on platform-oriented business models depends on market context.

Future research should further explore the role of $\mathrm{AI}$ in value co-creation. AI algorithms can further enrich value co-creation by integrating learning systems and personalized recommendations through feedback loops that foster user experience, engagement, and social interactions. Further empirical verification of our propositions using additional case studies is an additional task for future work. Up to now, the derived correlations are only described qualitatively. Therefore, it makes sense to develop a quantitative description further and evaluate the proposed framework in the future. Future work may also investigate whether additional market properties influence the impact of social interaction on value co-creation.

\section{References}

[1] Cusumano, M.A., A. Gawer, and D.B. Yoffie, The business of platforms: Strategy in the age of digital competition, innovation, and power, Harper Business New York, 2019.

[2] Yoffie, D.B., A. Gawer, and M.A. Cusumano, "A Study of More Than 250 Platforms Reveals Why Most Fail”, Harvard Business Review, 2019, pp. 5.

[3] Guggenberger, T., F. Möller, K. Boualouch, and B. Otto, "Towards a Unifying Understanding of Digital Business Models", PACIS 2020 Proceedings, 2020.

[4] Cusumano, M.A., A. Gawer, and D.B. Yoffie, "The Future of Platforms", MIT Sloan Management Review - Special Issue on Disruption 61(3), 2020, pp. 46-54.

[5] Parker, G., M.W. van Alstyne, and S.P. Choudary, Platform Revolution: How Networked Markets are Transforming the Economy--and How to Make Them Work for You, Norton \& Company, New York, 2016

[6] Alt, R., and H.-D. Zimmermann, "Electronic Markets on platform competition", Electronic Markets 29(2), 2019, pp. 143-149.

[7] Lusch, R.F., and S. Nambisan, "Service Innovation: A Service-Dominant Logic Perspective", MIS Quarterly 39(1), 2015, pp. 155-175.
[8] Schmidt, R., K. Kirchner, and L. Razmerita, "Understanding the Business Value of Social Information Systems A Research Agenda", 53rd Hawaii International Conference on System Sciences (HICSS), (2020), 2639-2648.

[9] Benkler, Y., The Wealth of Networks : How Social Production Transforms Markets and Freedom, Yale University Press, 2006.

[10] Surowiecki, J., The Wisdom of Crowds: Why the Many Are Smarter Than the Few and How Collective Wisdom Shapes Business, Economies, Societies and Nations, Anchor, 2005.

[11] Granovetter, M., "The Strength of Weak Ties", The American Journal of Sociology 78(6), 1973, pp. 1360 1380.

[12] Webster, J., and R.T. Watson, "Analyzing the past to prepare for the future: Writing a literature review", MIS Quarterly 26(2), 2002, pp. 494-508.

[13] Mallon, D., "A Systematic Literature Review of Digital Platform Business Models", Proceeding 16th International Conference on Wirtschaftsinformatik, (2021), 16.

[14] Alstyne, M.W.V., G.G. Parker, and S.P. Choudary, "Pipelines, Platforms, and the New Rules of Strategy", Harvard Business Review 94(4), 2016, pp. 54-62.

[15] Choudary, S.P., and M. Bonchek, "Three Elements of a Successful Platform Strategy", Harvard Business Review, 2013. https://hbr.org/2013/01/three-elements-of-asuccessful-platform

[16] Ben Letaifa, S., B. Edvardsson, and B. Tronvoll, "The role of social platforms in transforming service ecosystems", Journal of Business Research 69(5), 2016, pp. 1933-1938.

[17] McAfee, A., and E. Brynjolfsson, Machine, Platform, Crowd: Harnessing Our Digital Future, W. W. Norton \& Company, New York, 2017.

[18] Cennamo, C., "Competing in Digital Markets: A Platform-Based Perspective", Academy of Management Perspectives, 2021, pp. 28.

[19] Hui, P., and W.U. Li, "O2O e-commerce: power, patterns and prospects", Journal of South China University of Technology (Social Science Edition),(06), 2014, pp. 10 17.

[20] Eisenmann, T., G. Parker, and M.W. Van Alstyne, "Strategies for Two-Sided Markets", Harvard Business Review 84(10), 2006, pp. 92-101.

[21] Hermes, S., S. Pfab, A. Hein, J. Weking, M. Böhm, and H. Krcmar, "Digital Platforms and Market Dominance: Insights from a Systematic Literature Review and Avenues for Future Research", PACIS 2020 Proceedings, 2020.

[22] Alaimo, C., J. Kallinikos, and E. Valderrama-Venegas, "Platform Evolution: A Study of TripAdvisor", Proceedings of the 53rd Hawaii International Conference on System Sciences, (2020), 5462-5471.

[23] Camilleri, J., and B. Neuhofer, "Value co-creation and codestruction in the Airbnb sharing economy", International Journal of Contemporary Hospitality Management 29(9), 2017, pp. 2322-2340.

[24] Shapiro, C., S. Carl, and H.R. Varian, Information rules: a strategic guide to the network economy, Harvard Business Press, 1998. 
[25] Schmidt, R., R. Alt, and A. Zimmermann, "A Conceptual Model for Assistant Platforms", 54th Hawaii International Conference on System Sciences (HICSS), (2021), 4024-4033.

[26] Vargo, S., and R. Lusch, "Why 'service'?”, Journal of the Academy of Marketing Science 36(1), 2008, pp. 25-38.

[27] Vargo, S., P. Maglio, and M. Akaka, "On value and value co-creation: A service systems and service logic perspective", European Management Journal 26(3), 2008, pp. $145-152$.

[28] Yoo, K.-H., M. Sigala, and U. Gretzel, "Exploring TripAdvisor", In Open tourism. Springer, 2016, 239 255.

[29] Lusch, R., S. Vargo, and M. Tanniru, "Service, value networks and learning", Journal of the Academy of Marketing Science 38(1), 2010, pp. 19-31.

[30] Arthur, W.B., The nature of technology: What it is and how it evolves, Simon and Schuster, 2009.

[31] Okoli, C., and K. Schabram, "A guide to conducting a systematic literature review of information systems research", 2010.

[32] Hein, A., J. Weking, M. Schreieck, M. Wiesche, M. Böhm, and H. Krcmar, "Value co-creation practices in business-to-business platform ecosystems", Electronic Markets 29(3), 2019, pp. 503-518.

[33] Kim, J., and H. Choi, "Value co-creation through social media: a case study of a start-up company", Journal of Business Economics and Management 20(1), 2019, pp. $1-19$.

[34] Gammelgaard, B., C.B. Andersen, and M. Figueroa, "Improving urban freight governance and stakeholder management: A social systems approach combined with relationship platforms and value co-creation", Research in Transportation Business \& Management 24, 2017, pp. $17-25$.

[35] Haile, N., and J. Altmann, "Value creation in software service platforms", Future Generation Computer Systems 55, 2016, pp. 495-509.

[36] Austin, J.E., and M.M. Seitanidi, "Collaborative value creation: A review of partnering between nonprofits and businesses: Part I. Value creation spectrum and collaboration stages", Nonprofit and voluntary sector quarterly 41(5), 2012, pp. 726-758.

[37] Gawer, A., and M.A. Cusumano, "Industry platforms and ecosystem innovation", Journal of product innovation management 31(3), 2014, pp. 417-433.

[38] Kenney, M., and J. Zysman, "Work and value creation in the platform economy", In Work and Labor in the Digital Age. Emerald Publishing Limited, 2019.

[39] Ramaswamy, V., and K. Ozcan, "Offerings as digitalized interactive platforms: A conceptual framework and implications", Journal of Marketing 82(4), 2018, pp. 19-31.

[40] Suseno, Y., C. Laurell, and N. Sick, "Assessing value creation in digital innovation ecosystems: A Social Media Analytics approach", The Journal of Strategic Information Systems 27(4), 2018, pp. 335-349.

[41] Alaimo, C., and J. Kallinikos, "Computing the everyday: Social media as data platforms", The Information Society 33(4), 2017, pp. 175-191.

[42] Singaraju, S.P., Q.A. Nguyen, O. Niininen, and G. Sullivan-Mort, "Social media and value co-creation in multi- stakeholder systems: A resource integration approach", Industrial Marketing Management 54, 2016, pp. 44-55.

[43] Sorensen, A., L. Andrews, and J. Drennan, "Using social media posts as resources for engaging in value co-creation: The case for social media-based cause brand communities", Journal of Service Theory and Practice 27(4), 2017, pp. 898-922.

[44] Yu, C.-H., C.-C. Tsai, Y. Wang, K.-K. Lai, and M. Tajvidi, "Towards building a value co-creation circle in social commerce", Computers in Human Behavior 108, 2020, pp. 105476.

[45] Haile, N., and J. Altmann, "Structural analysis of value creation in software service platforms", Electronic Markets 26(2), 2016, pp. 129-142.

[46] Hamilton, M., V.D. Kaltcheva, and A.J. Rohm, "Social media and value creation: the role of interaction satisfaction and interaction immersion", Journal of Interactive Marketing 36, 2016, pp. 121-133.

[47] Ketonen-Oksi, S., J.J. Jussila, and H. Kärkkäinen, "Social media based value creation and business models", Industrial Management \& Data Systems 116(8), 2016, pp. $1820-1838$.

[48] Laukkanen, M., and N. Tura, "The potential of sharing economy business models for sustainable value creation", Journal of Cleaner production 253, 2020, pp. 120004.

[49] Tapscott, D., and A. Williams, Wikinomics: How Mass Collaboration Changes Everything, Portfolio, 2006.

[50] Wedel, M., and W.A. Kamakura, Market segmentation: Conceptual and methodological foundations, Springer Science \& Business Media, 2012.

[51] Brynjolfsson, E., Y.J. Hu, and M.D. Smith, "From niches to riches: Anatomy of the long tail", MIT Sloan Management Review 47(4), 2006, pp. 67-71.

[52] Peffers, K., T. Tuunanen, M.A. Rothenberger, and S. Chatterjee, "A design science research methodology for information systems research", Journal of management information systems 24(3), 2007, pp. 45-77.

[53] Kirchner, K., and L. Razmerita, "Managing the Digital Knowledge Work with the Social Media Business Value Compass", Proceedings of the 52nd Hawaii International Conference on System Sciences, Hawaii International Conference on System Sciences (HICSS) (2019), 6438 6447.

[54] Tura, N., A. Kutvonen, and P. Ritala, "Platform design framework: conceptualisation and application”, Technology Analysis \& Strategic Management 30(8), 2018, pp. 881-894.

[55] Otto, B., and M. Jarke, "Designing a multi-sided data platform: findings from the International Data Spaces case", Electronic Markets 29(4), 2019, pp. 561-580.

[56] Gelhaar, J., and B. Otto, "Challenges in the Emergence of Data Ecosystems.", PACIS, (2020), 175.

[57] Andreassen, T.W., L. Lervik-Olsen, H. Snyder, A.C.R. Van Riel, J.C. Sweeney, and Y. Van Vaerenbergh, "Business model innovation and value-creation: the triadic way", Journal of Service Management 29(5), 2018, pp. 883-906.

[58] Kapoor, R., "Ecosystems: broadening the locus of value creation", Journal of Organization Design 7(1), 2018, pp. 1-16. 